\title{
Ingenol Mebutate Treatment in a Patient with Gorlin Syndrome
}

\author{
Marco Stieger Robert E. Hunger \\ Department of Dermatology, University Hospital Inselspital, University of Bern, Bern, Switzerland
}

\author{
Key Words \\ Gorlin syndrome $\cdot$ Basal cell nevus syndrome $\cdot$ Ingenol \\ mebutate $\cdot$ Basal cell carcinoma $\cdot$ PTCH1 gene mutation . \\ Vismodegib
}

\begin{abstract}
Background: Gorlin syndrome, also known as the basal cell nevus syndrome (OMIM \#109400), is a rare autosomal-dominant genetic disease. The disease, which shows mutation of the patched receptor gene $(\mathrm{PTCH} 1)$ of the sonic hedgehog pathway, is characterized by developing multiple basal cell carcinomas (BCCs) in adolescent patients. Other clinical features include mandibular keratocysts, palmar and plantar pits, skeletal abnormalities and malformations central nervous system and genital tract. Gorlin-Goltz patients need multidisciplinary medical care and follow-up as well as genetic counseling if the patients want to have children. The treatment of multiple BCCs includes conventional surgery, micrographic Mohs surgery, cryotherapy, laser ablation, photodynamic therapy, imiquimod 5\% cream, 5-fluorouracil cream as well as the sonic hedgehog pathway inhibitor vismodegib. Case Report: We report the case of a 30-year-old woman seen in our dermatological department since 2003. All the above-mentioned modalities had been employed for her numerous BCCs. The patient grew wary of the surgical procedures because of the countless scars. We successfully treated multiple BCCs with ingenol mebutate without postinflammatory scarring. At 8-month follow-up, the patient shows no recurrence of the treated lesions. Conclusion: In-
\end{abstract}

genol mebutate can be used to treat (superficial) BCCs in patients with Gorlin-Goltz syndrome as an additional modality. Close clinical follow-up is recommended.

(C) 2016 S. Karger AG, Basel

\section{Introduction}

Gorlin syndrome, also known as the basal cell nevus syndrome (OMIM \#109400), is a rare autosomal-dominant genetic disease. The characteristic multiorgan abnormalities are caused by mutations of the patched receptor gene (PTCH1), a tumor suppressor gene, on chromosome arm 9q. PTCH1 inhibits signaling by the membrane protein Smoothened (SMO). The loss-of-function mutation of PCHT1 results in an elevated activation of the sonic hedgehog pathway, which activates transcription factors such as GLI1. GLI1 induces cell cycle progression and cell proliferation and is associated in development of basal cell carcinoma (BCC) and medulloblastoma. Up to $40 \%$ of the patients show a de-novo mutation with negative family history. The prevalence is 1:60,000 with an equal frequency in women and men $[1,2]$.

Most patients develop multiple BCCs already in adolescence, which should raise the suspicion of GorlinGoltz syndrome. The BCCs are usually located on the face and trunk, but also occur on sun-protected areas. All histological subtypes from superficial to infiltrative and morphoeic BCC can be found. Aggressive forms such as the locally destroying ulcus terebrans are very rare. Other

\section{KARGER}

E-Mail karger@karger.com

www.karger.com/drm
C 2016 S. Karger AG, Basel

$1018-8665 / 16 / 2327-0029 \$ 39.50 / 0$
Marco Stieger

Department of Dermatology

University Hospital Inselspital, University of Bern

$\mathrm{CH}-3010$ Bern (Switzerland)

E-Mail marco.stieger@insel.ch 
1

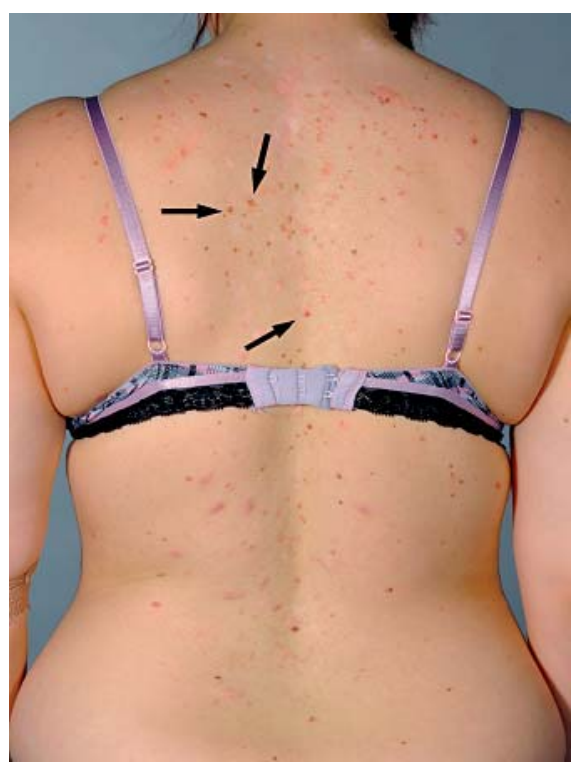

2

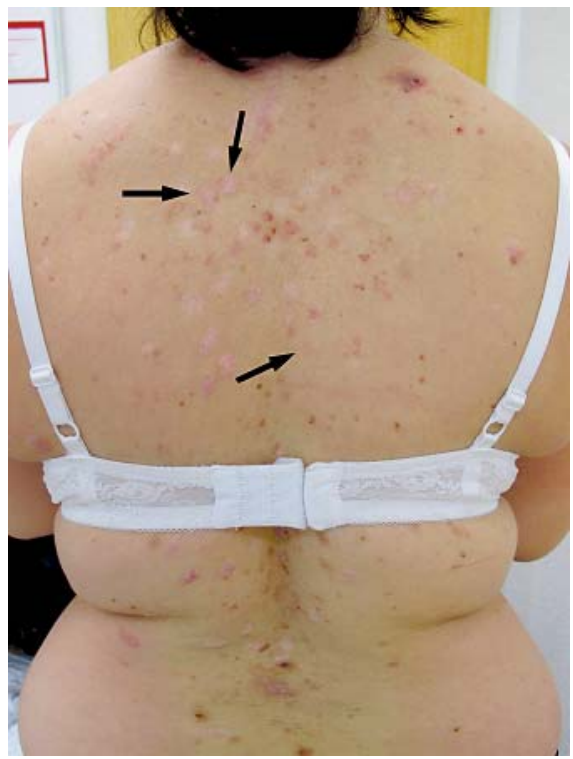

Fig. 1. Multiple clinically diagnosed BCC (arrows).

Fig. 2. Complete resolution of the BCC after topical treatment with ingenol mebutate gel (arrows). cerebri, multiple ovarian cysts and fibromas and the radiologic evidence of odontogenic keratocysts. Genotyping of the $\mathrm{PTCH} 1$ gene detected a heterozygous mutation. Over 10 years, the patient was treated with numerous procedures such as micrographic Mohs surgery, conventional surgery, photodynamic therapy and topical therapy with imiquimod cream. In 2014, we initiated a systemic therapy with vismodegib, which showed a pronounced response with decrease of most of the BCC. The patient developed alopecia, dysgeusia and pronounced long-lasting fatigue. Eventually, the patient decided to stop vismodegib therapy after 6 months on account of side effects impairing her quality of life. BCC recurred after 3 months but the patient was tired of surgery and asked for an alternative therapy. Cryosurgery was very painful and also resulted in extensive scarring. We treated multiple BCCs on her back with 500 $\mu \mathrm{g} / \mathrm{g}$ of ingenol mebutate gel (fig. 1). Her husband applied the gel for 2 consecutive days. She reported a local inflammatory reaction, which healed after 2 weeks. Clinically, the treated BCCs showed complete resolution without scarring (fig. 2). The patient repeated the treatment on a regular basis without affecting her daily life and work. During the follow-up over 8 months, no recurrence of the treated BCC was detected. Of course, occasional surgery of more invasive BCCs was not completely unavoidable but the patient was happy to be able to treat many BCCs on her own without a great effort and side effects.

\section{Conclusion}

Ingenol mebutate seems a suitable off-label option to treat (superficial) BCCs in patients with Gorlin syndrome. The treatment is easy to manage and patients appreciate being able to treat autonomously. 


\section{Statement of Ethics}

Informed consent for image acquisition, biopsy specimen sampling and treatment (including evidence-based and off-label use) was obtained from the patient.

\section{References}

1 Bonifas JM, Pennypacker S, Chuang PT, et al: Activation of expression of hedgehog target genes in basal cell carcinomas. J Invest Dermatol 2001;116:739-742.

2 Pino LC, Balassiano LK, et al: Basal cell nevus syndrome: clinical and molecular review and case report. Int J Dermatol 2016;55:367375.

\section{Disclosure Statement}

The authors declare no conflicts of interest.
3 Acocella A, Sacco R, Bertolai R, Sacco N: Genetic and clinicopathologic aspects of GorlinGoltz syndrome (NBCCS): presentation of two case reports and literature review. Minerva Stomatol 2009;58:43-53.

4 Baliga SD, Rao SS: Nevoid-basal cell carcinoma syndrome: a case report and overview on diagnosis and management. J Maxillofac Oral Surg 2010;9:82-86.
5 Weiss GJ, Tibes R, et al: Long-term safety, tolerability, and efficacy of vismodegib in two patients with metastatic basal cell carcinoma and basal cell nevus syndrome. Dermatol Reports 2011;3:e55.

6 Cantisani C, Paolino G, et al: Superficial basal cell carcinoma successfully treated with ingenol mebutate gel $0.05 \%$. Dermatol Ther 2014;27:352-354. 